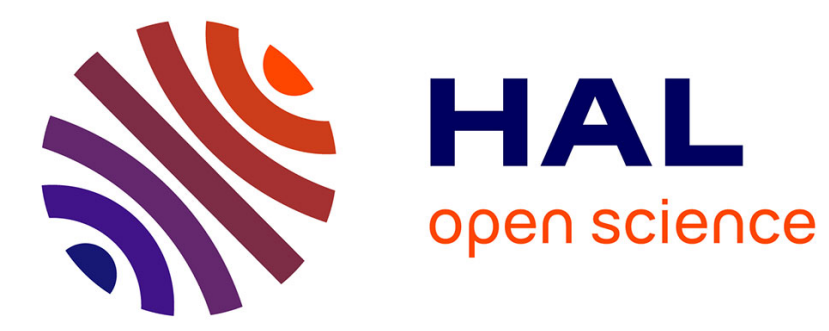

\title{
Quantitative WD-XRF calibration for small ceramic samples and their source material
}

François de Vleeschouwer, Virginie Renson, Philippe Claeys, Karin Nys, Richard Bindler

\section{- To cite this version:}

François de Vleeschouwer, Virginie Renson, Philippe Claeys, Karin Nys, Richard Bindler. Quantitative WD-XRF calibration for small ceramic samples and their source material. Geoarchaeology: An International Journal, 2011, vol. 26, pp. 440-450. 10.1002/gea.20353 . hal-00987098

\section{HAL Id: hal-00987098 https://hal.science/hal-00987098}

Submitted on 5 May 2014

HAL is a multi-disciplinary open access archive for the deposit and dissemination of scientific research documents, whether they are published or not. The documents may come from teaching and research institutions in France or abroad, or from public or private research centers.
L'archive ouverte pluridisciplinaire HAL, est destinée au dépôt et à la diffusion de documents scientifiques de niveau recherche, publiés ou non, émanant des établissements d'enseignement et de recherche français ou étrangers, des laboratoires publics ou privés. 


\section{OATAO \\ Open Archive Toulouse Archive Ouverte}

\section{Open Archive TOULOUSE Archive Ouverte (OATAO)}

OATAO is an open access repository that collects the work of Toulouse researchers and makes it freely available over the web where possible.

This is an author-deposited version published in : http://oatao.univ-toulouse.fr/ Eprints ID : 11501

To link to this article : doi:10.1002/gea.20353

URL : http://dx.doi.org/10.1002/gea.20353

To cite this version : De Vleeschouwer, François and Renson, Virginie and Claeys, Philippe and Nys, Karin and Bindler, Richard Quantitative WD-XRF calibration for small ceramic samples and their source material. (2011) Geoarchaeology, vol. 26 ( ${ }^{\circ} 3$ ). pp. 440-450. ISSN 0883-6353

Any correspondance concerning this service should be sent to the repository administrator: staff-oatao@listes-diff.inp-toulouse.fr 


\title{
Quantitative WD-XRF Calibration for Small Ceramic Samples and Their Source Material
}

\section{François De Vleeschouwer, ${ }^{1,2, *}$ Virginie Renson, ${ }^{3}$ Philippe Claeys, ${ }^{3}$ Karin Nys, ${ }^{4}$ and Richard Bindler ${ }^{1}$}

\begin{abstract}
A wavelength-dispersive X-ray fluorescence (WD-XRF) calibration is developed for small powdered samples $(300 \mathrm{mg})$ with the purpose of analyzing ceramic artifacts that might be available only in limited quantity. This is compared to a conventional calibration using a larger sample mass $(2 \mathrm{~g})$. The comparison of elemental intensities obtained in both calibrations shows that the decrease in analyzed sample mass results in a linear decrease in measured intensity for the analyzed elements. This indicates that the small- and large-sample calibrations are comparable. Moreover, the elemental contents of four ceramic sherds and two potential clay sources fall well within the range of the certified reference materials that are the basis of the calibration curves. The advantage with the analytical method presented here is that it is rapid and requires only a small amount of sample that can easily be re-used for further analyses. This method has great potential in ceramic provenance studies. () 2011 Wiley Periodicals, Inc.
\end{abstract}

\section{INTRODUCTION}

In archaeometry a wide range of chemical techniques has been used to assess the geochemical content of various archaeological objects (e.g., Adan-Bayewitz, Asaro, \& Giaque, 1999; Szökefalvi-Nagi et al., 2004; Asaro \& Adan-Bayewitz, 2007; Cultrone et al., 2010; Mazar et al., 2010; Renson et al., 2011). Among these objects are ceramic sherds, which, if accurately quantified for their elemental content and analyzed in a multivariate statistical approach, can provide information on the source and trading of ceramics in ancient times. The main problem of analyzing archaeological objects is that, for conservation reasons, the availability of sample is often limited. In the case of ceramics, the sample often consists of small fragments found on archaeological sites or retrieved from collections. Archaeometrists are therefore in

*Corresponding author; E-mail: francois.devleeschouwer@ensat.fr. 
constant search for analytical techniques that allow elemental quantification on a minimum amount of material.

$\mathrm{X}$-ray fluorescence (XRF) is an analytical technique that has been widely used in many industrial, environmental, geological, and archaeological investigations (see West et al., 2010, for a recent review of XRF applications). Among the applications, XRF has been widely used in the earth sciences (e.g., Potts, 1987, and references therein; Gardner, 1990; Cheburkin, Frei, \& Shotyk, 1997; Zambello \& Enzweiller, 2002; West et al., 2010, and references therein) and has been developed to analyze vegetation samples (e.g., Cheburkin \& Shotyk, 1996; Margui, Hidalgo, \& Queralt, 2005) and liquid matrices (e.g., Cumming \& McDonald, 1985; Varga et al., 1995; Oprea et al., 2009). In archaeological studies, XRF has a wide range of applications, and samples can be potentially re-used for further analysis depending on the sample preparation (e.g., Adan-Bayewitz, Asaro, \& Giaque, 1999; Hein et al., 2004; Craig et al., 2007; Tripathi \& Rajamani, 2007; Cultrone et al., 2010; West et al., 2010, and references therein). The common drawbacks of XRF are the so-called matrix effects, which are principally caused by the composition, grain size, and mineralogy of the sample. A way to minimize these effects is to finely powder the samples and to apply subsequent pretreatments such as lithium borate fusion or pelletization using a wax binder (Potts, 1987). However, these processes alter the properties of the samples, which then cannot be re-used for further analyses. Classical XRF on powder, pellets, or fused beads also requires several grams of sample to achieve an accurate elemental quantification (e.g., Zambello \& Enzweiller, 2002; Cultrone et al., 2010). This limits its application to archaeological artifacts that are available only in sufficiently large quantity. For small samples, direct analysis of powdered material would therefore be generally preferred. Such an application needs to be carefully developed to provide accurate elemental quantification (Adan-Bayewitz, Asaro, \& Giaque, 1999).

New generations of wavelength-dispersive XRF (WD-XRF) offer the potential to decrease the quantity of material by carefully developing calibrations on samples as small as a few hundred milligrams. A common WD-XRF setup allows the determination of major and selected trace elements without specific spectrometric design. In this short note we provide the details of a calibration that was purposely developed for quantifying selected elements in small ceramic fragments and their potential raw materials. We present some of the technical aspects of the selection and preparation of the certified reference materials (CRMs) as well as a specific calibration developed to optimize WD-XRF for ceramic matrices and their source materials. This specific calibration for small sample mass ( $300 \mathrm{mg}$ ) is validated by comparing the intensities obtained with a conventional calibration (i.e., using 2-g samples).

\section{METHODOLOGY}

\section{Selection of Certified Reference Materials}

Thirty-five commercially available CRMs were selected from our laboratory stock. All our CRMs are finely powdered and stored in desiccators. They consist of sedimentary and igneous rocks (NIST1d, NIST70a, NIST278, NIST2780, NIST688), river 
sediments (NIST8704, STSD3), lake sediments (LKSD1, LKSD4, BIL1, JLK1), estuarine sediments (NIST1646a), and marine sediments (NIST1944, NIST2702, NIST2703, MAG1, PACS2, MESS3) as well as sands (NIST81a, NIST1413), clays (NIST97b, NIST98b, NIST679), and soils (SO2, SO3, SO4, NIST2711, NIST2586, NCSDC73325, NCSDC73326, JSO1) from sedimentary outcrops, and coal fly ash (JCFA1, NIST1633a, NIST1633b, ZUK1), the latter type being added to extend the range of various trace elements. Rather than exclusively choosing fine sediments, we have included several sediment and rock types to represent mixed matrices (i.e., fine material and temper) that may be found in ceramics (Rapp, 2009).

\section{Sample Preparation}

All the analyses were carried out directly on CRM powders. Two calibrations were developed: one based on $2 \mathrm{~g}$ of each CRM, as commonly done in XRF analyses, and a second based on $300 \mathrm{mg}$ of powder that was specifically developed here. For the first calibration, $2 \mathrm{~g}$ of dried and homogenized loose powder was transferred to 40 -mm-opening plastic cups with a $2.5-\mu \mathrm{m}$ transparent mylar film at its base. These samples were placed in 36-mm-opening metallic cup holders for analysis. The challenging part of this study was the development of the second calibration, using $300 \mathrm{mg}$ of powder, which was transferred to a plastic cup with a 10-mm opening, also with a $2.5-\mu \mathrm{m}$ mylar film at the base. In these small cups the powder was slightly compressed manually to reduce porosity effects. These plastic cups were subsequently loaded in a metallic cup holder with an opening (i.e., analytical) diameter of $8 \mathrm{~mm}$.

\section{XRF Optimization}

All the analyses were conducted using a Bruker S8-Tiger WD-XRF analyzer equipped with a Rh anticathode X-ray tube, four analyzing crystals (XS-55, PET, LIF200, LIF220), a flow proportional counter (for light elements), and a scintillation counter (for heavy elements). Analyses were performed under helium atmosphere to avoid powder loss in the analytical chamber, which may occur under vacuum conditions. The main parameters, used for each calibration and each element, are reported in Table I. Such a WD$\mathrm{XRF}$ setup allows the determination of a wide range of elements, generally from $\mathrm{C}$ to $\mathrm{U}$. In this study, the following elements were selected: $\mathrm{Na}, \mathrm{Mg}, \mathrm{Al}, \mathrm{Si}, \mathrm{P}, \mathrm{S}, \mathrm{K}, \mathrm{Ca}, \mathrm{Ti}, \mathrm{V}$, $\mathrm{Mn}, \mathrm{Fe}, \mathrm{Ni}, \mathrm{Cu}, \mathrm{Zn}, \mathrm{Br}, \mathrm{Rb}, \mathrm{Sr}, \mathrm{Ba}$, and $\mathrm{Pb}$. This selection is based on the certified values available in each CRM, which are matched with the expected detectable concentrations of our WD-XRF spectrometer. The WD-XRF resolution and sensitivity have been optimized by combining the proper collimators, crystals, and counters for each element (Table I). The peak acquisition time was optimized using the built-in SpectraPlus ${ }^{\circledR}$ software interface, which calculates the time necessary to achieve an average selected detection limit. The acquisition time varies, therefore, among elements as well as among concentrations of a given element (i.e., the lower the concentration, the greater the time). To avoid any excessively long acquisition times, a maximum time was set for each element, which varies from 30 to $100 \mathrm{~s}$ (Table I). The background measurement times have been fixed manually, generally at $10 \mathrm{~s}$, except for a few trace elements 


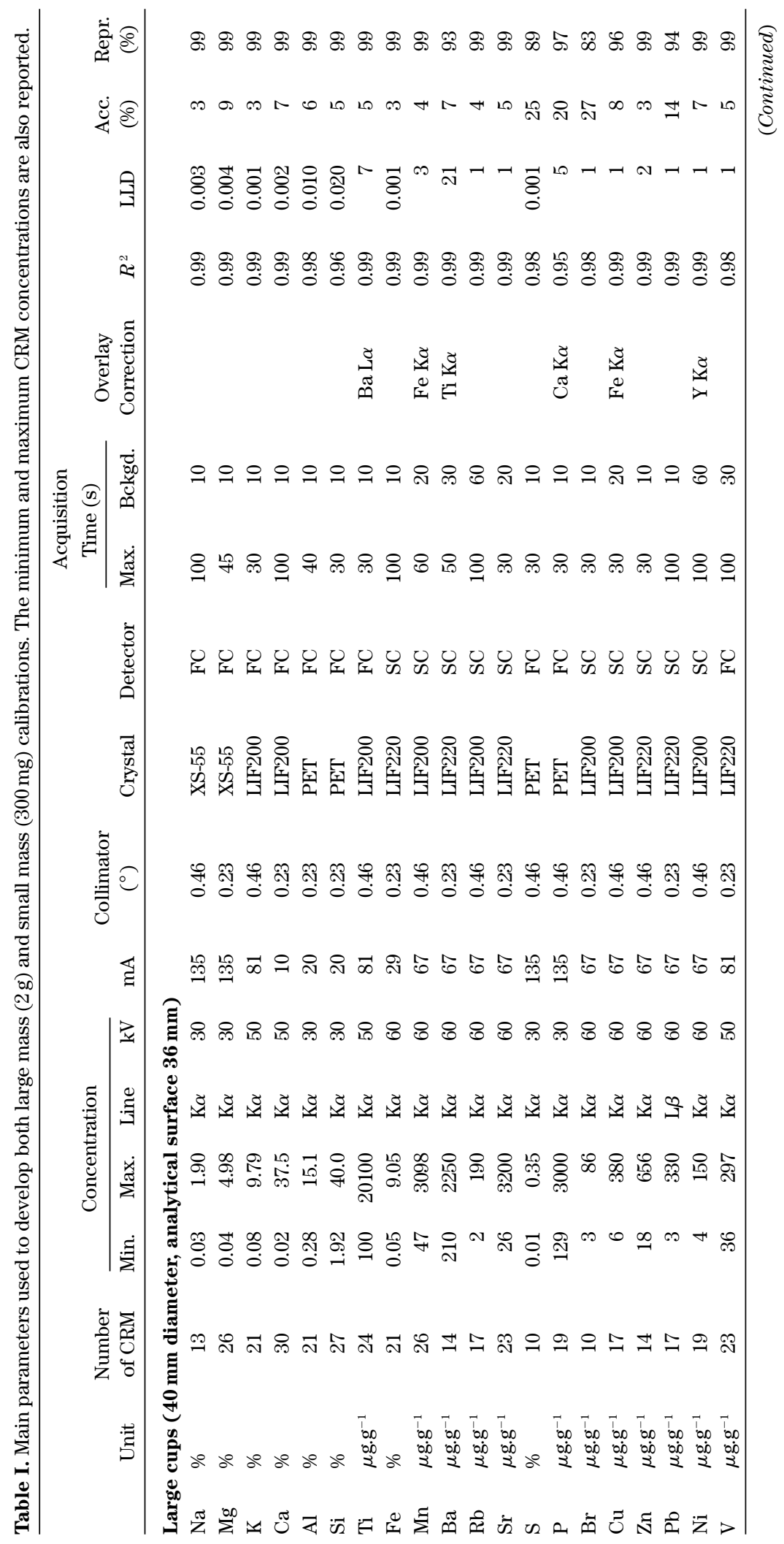




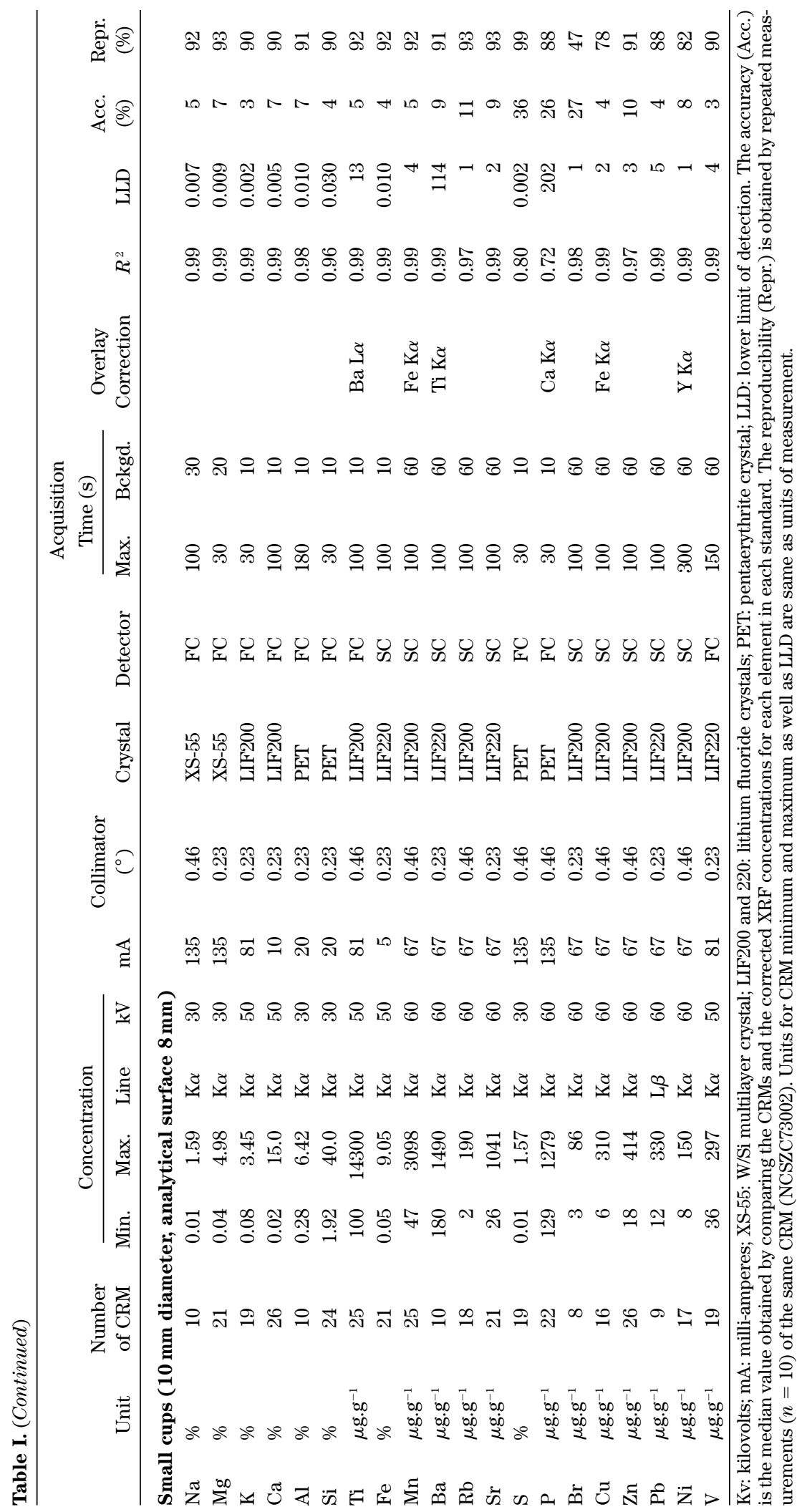


where intensities were expected to be low (see Table I). The overall measurement time is about $40 \mathrm{~min}$ per sample (i.e., 36 samples/ $24 \mathrm{~h}$ ).

The calibration procedure is achieved in two steps: (1) all the CRMs are scanned at standard conditions to allow for optimization of sensitivity, resolution, and detection limits (see preceding), and then (2) a full analysis of the CRMs selected to give the best fit (i.e., to minimize standard error) of the ultimate calibration line is conducted. This necessary selection depends on (a) the available certified values; (b) the behavior of each CRM matrix in both calibrations ( $2 \mathrm{~g}$ loose powder vs. $300 \mathrm{mg}$ pressed powder); and (c) the targeted standard error, which can be decreased by carefully removing values slightly off the calibration line without changing its slope. This selection process explains why, for a given element, the number of CRMs may vary between both calibrations (Table I). A posteriori corrections are also applied. They are of two types: (1) a software-built matrix correction that takes into account the inter-elemental interferences in the sample (i.e., a fluorescence X-ray originating from an element that causes electronic transitions in elements with lower energies), and (2) overlay corrections that are applied individually for peak overlaps commonly encountered in XRF spectra (see Table I). Finally, a quantitative calibration curve has been developed for each element by using a linear regression between the corrected intensities and the CRM concentrations through the built-in software.

In addition, an in-house standard (STG) is measured daily to check the analytical performance of the XRF. Three additional internal standards (SQ1, SQ3, Ausmon) are used to monitor the long-term (yearly) drift of the device and to correct intensities if necessary. Lower limits of detections (LLD) are calculated as follows:

$$
L L D=\frac{3}{S_{i}} \sqrt{\frac{I_{b}}{T_{b}}}
$$

where $S_{i}$ is the analytical sensitivity (Cps/concentration), $I_{b}$ is the background intensity (in kilocounts per second, Cps), and $T_{b}$ is the background measurement time (s). It is also possible to recalculate a corrected concentration for each CRM by plotting its corrected intensity on the calibration line. This value was used to monitor the total analytical accuracy for each CRM and each element as follows:

$$
\text { Accuracy }=\frac{\sqrt{\left(C_{C R M}-C_{C O R}\right)^{2}}}{C_{C R M}} \times 100
$$

where $C_{C R M}$ is the certified concentration and $C_{c o r}$ is the corrected (i.e., recalculated) concentration. Finally, reproducibility has been assessed for both calibrations using an external CRM (which is not included in the calibration process) with a similar matrix (NCS-ZC73002, soil). Multiple $(n=10)$ runs of this CRM provide a reproducibility expressed as follows:

$$
\text { reproducibility }(\%)=\frac{\text { Average } C_{n=10}-\text { Stdeva } C_{n=10}}{\text { Average } C_{n=10}} \times 100
$$




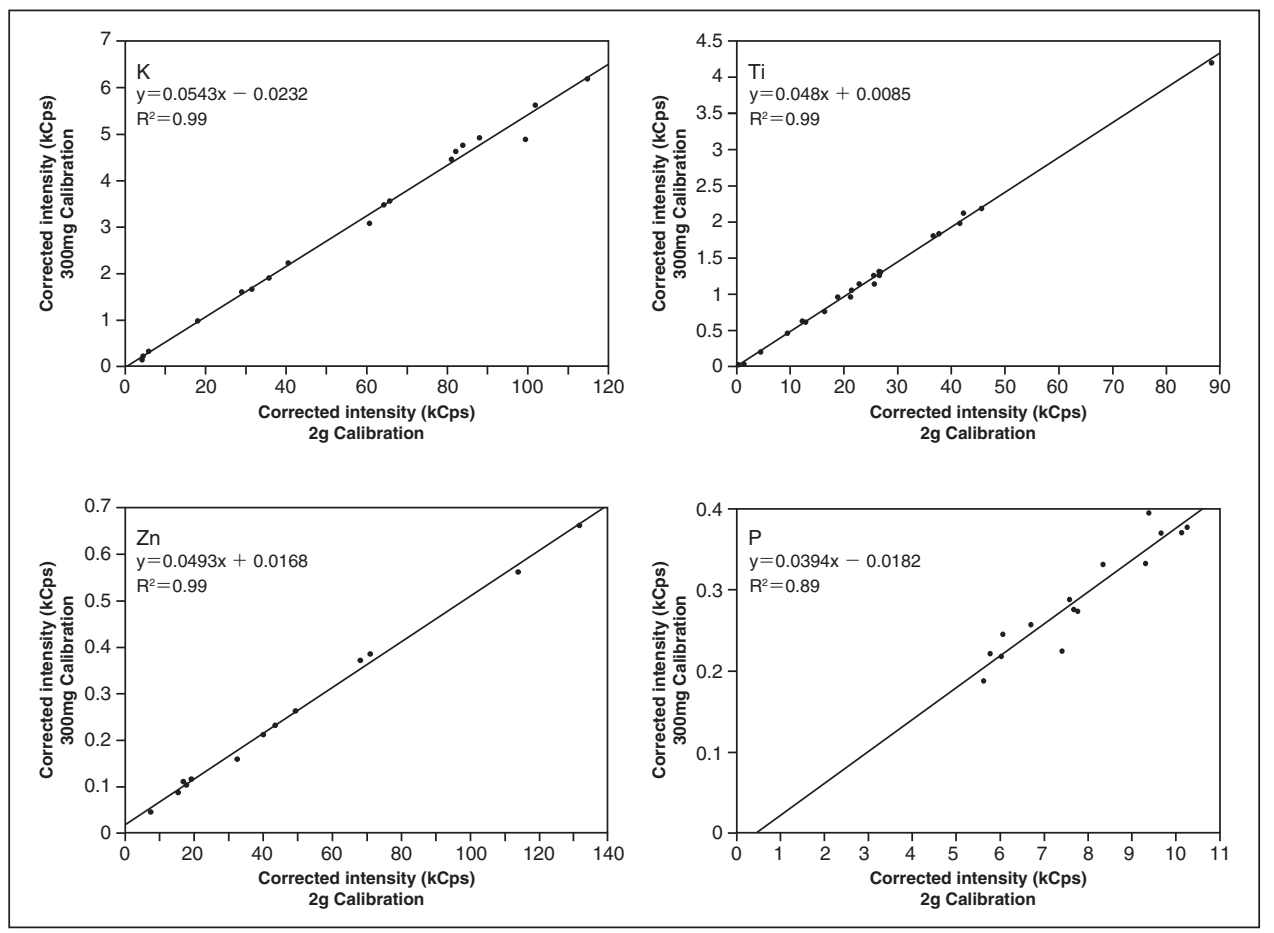

Figure 1. Biplot comparison of intensities (kilocounts per second-kCps) obtained using the large and the small calibrations for K, Ti, Zn, and P. Black dots represent the CRMs.

where Average and Stdeva represent the mean $(n=10)$ CRM concentration and standard deviation, respectively. Results, as well as detection limits, accuracies, and reproducibilities are reported in Table I.

\section{RESULTS AND DISCUSSION}

Potassium (K), titanium (Ti), zinc (Zn), and phosphorus (P) were chosen to illustrate the comparison of the two calibrations and the reliability of the small-sample calibration. Potassium (major constituent) and Ti (minor constituent) were selected because they represent two important lithogenic elements commonly used in provenance studies. Zinc illustrates the behavior of heavy metals and phosphorus a calibration that displays greater uncertainty. Figure 1 presents biplots of the corrected intensities for both large-cup and small-cup calibrations. Because the number of CRMs for a given element differs between the large-cup and small-cup calibrations, only the intensities of the CRM common to each calibration are plotted together. For most of the studied elements, the CRM intensities plot nicely along a line $\left(R^{2} \geq\right.$ 0.89 for elements in Figure 1), which indicates that decreasing the amount of material results in a linear decrease in the peak intensities. The intensities generally 
decrease by a factor 15 to 25 from the 2-g to the $300-\mathrm{mg}$ samples. However, both elemental peak and background intensities decrease, allowing for a good peakbackground resolution. This is also supported by the low and comparable LLD found in both calibrations: a few tens of $\mu \mathrm{g} \mathrm{g}^{-1}$ and a few $\mu \mathrm{g} \mathrm{g}^{-1}$ for major and trace elements, respectively (Table I). These values are generally below or equal to previously reported data (Cheburkin, Frei, \& Shotyk, 1997; Boyle, 2000; Hein et al., 2002; Zambello \& Enzweiller, 2002; Cultrone et al., 2010). Similarities between the two calibrations can also be observed for the accuracies, which remain within $\leq 10 \%$ for most elements except for S, P, and Br. These accuracy values are slightly below values encountered in the literature (Cheburkin, Frei, \& Shotyk, 1997; Boyle, 2000; Zambello \& Enzweiller, 2002; Cultrone et al., 2010). Improvements in both LLD and accuracy can be explained by the continuous analytical development of commercially available XRF and the careful selection of appropriate CRMs and WD-XRF optimization. Lower detection limits and accuracies have been reported by Adan-Bayewitz, Asaro, \& Giaque (1999), who have used a specific Ag-cathode XRF setup. While such a configuration results in lower LLD and accuracies, it does not allow the determination of all major elements, which is crucial in provenance studies. Moreover, such a configuration is of limited availability compared to largely commercially available Rh-cathode WD-XRF. Compared to the large-cup calibration, reproducibility values are generally $5-10 \%$ lower for the small-cup calibration (Table I). This can be explained by the smaller analytical surface (8-mm vs. 36-mm opening), which results in a lower signal integration. However, these reproducibilities are fully satisfactory, with values mostly above $90 \%$, except for a very few elements (e.g., $\mathrm{Cu}: 78 \%$ and Ni: $82 \%$ ). One notable exception is $\mathrm{Br}$, which shows rather poor reproducibility (47\%). This may be explained by (1) the low concentration encountered in the CRM analyzed for this test $(2.8 \mu \mathrm{g}$ $\left.\mathrm{g}^{-1}\right)$, (2) the relatively low amount of CRM with certified values for $\operatorname{Br}(n=8$; see Table I), and (3) the low intensities (0-0.15 kilocounts per second) recovered for this element. Bromine concentrations should therefore not be taken as a fully quantified element using the small-cup calibration, but rather as indicative of large variations, which may be taken into account when using multivariate statistics, where covariance is considered rather than absolute values.

The linear relationship between the two calibration intensities also implies that results are independent of the calibration. In other words, the results of samples quantified with one calibration can be compared directly with the results obtained using the other. In the specific context of a provenance study, it is therefore possible to compare source materials where a large amount of material is available, such as soils, rocks, and sediments, with small ceramic sherds (where the amount of material may be limited) using the two different calibrations based on the same CRM, but differing in the amount of material ( $2 \mathrm{~g}$ vs. $300 \mathrm{mg}$ ) and analytical surface (36 mm vs. $8 \mathrm{~mm}$ ). Both major and trace elements display linear behaviors similar to $\mathrm{K}$, Ti, and Zn, with low intercept offsets. Two elements display poor agreement: $\mathrm{P}$ and $\mathrm{Ba}$. However, it should be noted that these two elements can be accurately quantified using the large-cup calibration. The comparison between the two calibrations is poor because $\mathrm{P}$ and $\mathrm{Ba}$ are inaccurately quantified using the small-cup calibration. This can be explained by a narrow CRM concentration range for $\mathrm{P}$ and bad 


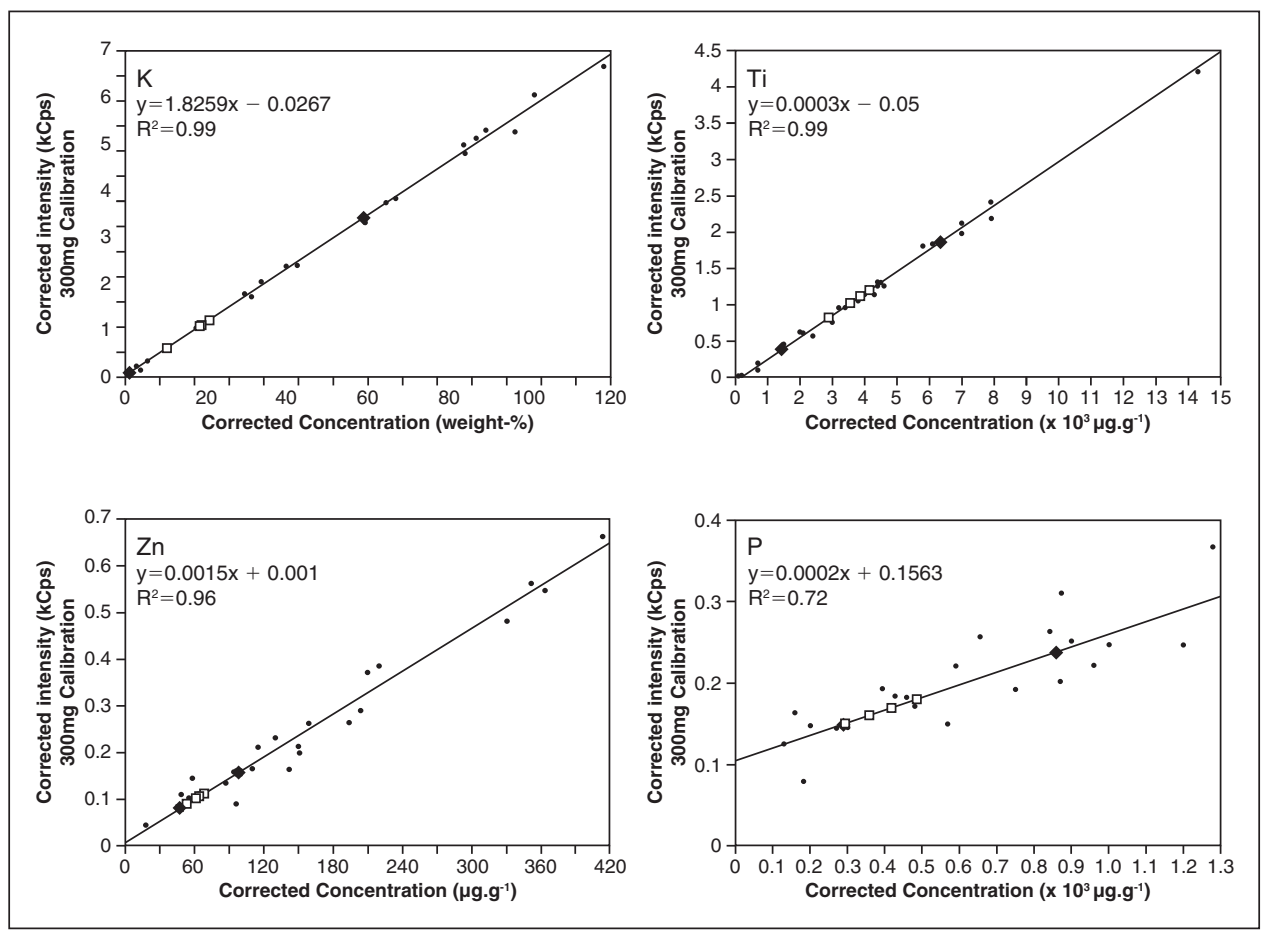

Figure 2. Calibration lines (corrected intensities in kCps vs. CRM concentrations) obtained using the small cups for $\mathrm{K}, \mathrm{Ti}, \mathrm{Zn}$, and P. Black dots represent the CRM. Open squares represent the pottery sherds. Black diamonds represent two potential raw materials from Cyprus.

peak-background ratios for $\mathrm{P}$ and $\mathrm{Ba}$. Caution is therefore required when using these elements in ceramic provenance studies where their concentrations have been measured with the technique described here. However, in provenance studies where multivariate statistical approaches are often used to identify pottery groups and provenances, the loss of two minor elements out of a total suite of 20 elements will not influence significantly the results of multivariate statistical calculations.

The small-cup calibration curves for $\mathrm{K}, \mathrm{Ti}, \mathrm{Zn}$, and $\mathrm{P}$ are reported in Figure 2. To briefly illustrate the applicability of the small-cup calibration to ceramic artifacts, the elemental concentrations of four Cypriot Late Bronze age ceramic sherds and two potential raw materials have been measured; complete analyses of those samples will be presented in a separate publication. The concentration ranges found in the sherds and sediments are well enclosed within the CRM concentration ranges (Figure 2). As shown by the $\mathrm{Zn}$ biplots, trace metal concentrations are found to be relatively low in these sherds and sediments. This is also the case for the Pb concentrations $(<15 \mu \mathrm{g}$ $\mathrm{g}^{-1}$, not shown here), which may potentially limit the applicability of XRF to trace metals in ceramic provenance studies. These considerations regarding elemental chemistry need, however, to be confirmed by the analysis of a wider range of ceramic 
artifacts in order to better explore the concentration range of each element using WD-XRF.

One last but major advantage of WD-XRF, besides providing quantitative data on a large amount of elements (here 18 to 20 elements), is that these same powdered samples can be re-used for further analyses such as mineralogy determination by $\mathrm{X}$-ray diffraction, or isotopic analyses. The calibration developed here renders this re-use possible even on very small samples. It should finally be emphasized that while $300 \mathrm{mg}$ of sample powder is sufficient, one should make sure that such a small amount is sufficiently representative of the whole object.

\section{CONCLUSIONS}

This study presents a rapid, non-destructive (i.e., the powdered samples can be re-used) WD-XRF protocol developed for small sample masses, down to $300 \mathrm{mg}$ of dry powder. This protocol allows the accurate determination of major $(\mathrm{Na}, \mathrm{Mg}, \mathrm{Al}$, $\mathrm{Si}, \mathrm{K}, \mathrm{Ca}, \mathrm{Fe}$ ), minor (Ti, $\mathrm{P}, \mathrm{S}, \mathrm{Mn}$ ), and trace (V, Ni, Cu, $\mathrm{Zn}, \mathrm{Br}, \mathrm{Rb}, \mathrm{Sr}, \mathrm{Ba}, \mathrm{Pb}$ ) elements. With the exception of three elements $(\mathrm{P}, \mathrm{Ba}, \mathrm{Br})$, this specific calibration is fully comparable to conventional calibration using larger amounts of sample (2 $\mathrm{g}$ ). Lower limits of detections and accuracies are comparable to, if not below, those found in the literature using similar XRF designs. Such a small sample calibration developed for pottery sherds may be widely applied in the field of ceramic provenance studies.

The WD-XRF acquisition, setup, and optimization was made possible through a research grant from the Kempe Foundation to R.B., which also provided a post-doc fellowship to F.D.V. Additional support was provided by the Research Foundation Flanders (FWO grants KN137 to K.N. and G.0585.06 to P.C.), the Research Council of the Vrije Universiteit Brussel (grant HOA11 to K.N. and P.C.), and the Swedish Research Council (grant to R.B.). We also thank Dr. Flourentzos, Director of the Department of Antiquities, Cyprus, for granting export permission for the sherds from Hala Sultan Tekke-Vyzakia. The comments of M. Kylander, A. Martinez-Cortizas, as well as two anonymous reviewers and editor G. Huckleberry improved an earlier version of this manuscript.

\section{REFERENCES}

Adan-Bayewitz, D., Asaro, F., \& Giaque, R.D. (1999). Determining pottery provenance: Application of a new high-precision X-ray fluorescence method and comparison with instrumental neutron activation analysis. Archaeometry, 41, 1-24.

Asaro, F., \& Adan-Bayewitz, D. (2007). The history of the Lawrence Berkeley National Laboratory instrumental neutron activation analysis programme for archaeological and geological materials. Archaeometry, 49, 201-214.

Boyle, J.F. (2000). Rapid elemental analysis of sediment samples by isotope source XRF. Journal of Paleolimnology, 23, 213-221.

Cheburkin, A.K., \& Shotyk, W. (1996). An energy-dispersive miniprobe multielement analyser (EMMA) for direct analyses of $\mathrm{Pb}$ and other trace elements in peats. Fresenius Journal of Analytical Chemistry, 354, 688-691.

Cheburkin, A.K., Frei, R., \& Shotyk, W. (1997). An energy-dispersive miniprobe multielement analyser (EMMA) for direct analysis of trace and chemical age dating of single mineral grains. Chemical Geology, 135, 75-87. 
Craig, N., Speakman, R.J., Popelka-Filcoff, R.S., Glascock, M.D., Robertson, J.D., Shackley, M.S., \& Aldenderfer, M.S. (2007). Comparison of XRF and PXRF for analysis of archaeological obsidian from southern Peru. Journal of Archaeological Science, 34, 2012-2024.

Cultrone, G., Molina, E., Grifa, C., \& Sebastián, E. (2010). Iberian ceramic production from Basti (Baza, Spain): First geochemical, mineralogical and textural characterization. Archaeometry, in press. DOI: 10.1111/j.1475-4754.2010.00545.x.

Cumming, G., \& McDonald, I.G. (1985). The determination of iron in lubricating oils by X-ray fluorescence spectrometry. Wear, 103, 57-66.

Gardner, L.R. (1990). Geochemical analysis of silicate rocks and soils by XRF using pressed powders and a two-stage calibration procedure. Chemical Geology, 88, 169-182.

Hein, I., Day, P.M., Cau Ontivreros, M.A., \& Kilikoglou, V. (2004). Red clays from central and eastern Crete: Geochemical and mineralogical properties in view of provenance studies on ancient ceramics. Applied Clay Science, 24, 245-255.

Hein, A., Tsolakidou, A., Iliopoulos, I., Mommsen, H., Buxeda i Garrigós, J., Montana, G., \& Kilikoglou, V. (2002). Standardisation of elemental analytical technique applied to provenance studies of archaeological ceramics: An interlaboratory calibration study. The Analyst, 127, 542-553.

Marguí, E., Hidalgo, M., \& Queralt, I. (2005). Multielemental fast analysis of vegetation samples by wavelength dispersive X-ray fluorescence spectrometry: Possibilities and drawbacks. Spectrochimica Acta Part B, 60, 1363-1372.

Mazar, E., Horowitz, W., Oschima, T., \& Goren, Y. (2010). A cuneiform tablet from the Ophel in Jerusalem. Israel Exploration Journal, 60, 4-21.

Oprea, C., Maslov, O.D., Gustova, M.V., Belov, A.G., Szalanski, P.J., \& Oprea, I.A. (2009). IGAA and XRF methods used in oil contamination research. Vacuum, 83, S162-S165.

Potts, P.J. (1987). A handbook of silicate rock analysis. Glasgow: Blackie \& Son Limited.

Rapp, G.R. (2009). Archaeomineralogy, 2nd ed. Heidelberg: Springer.

Renson, V., Coenaerts, J., Nys, K., Mattielli, N., Vanhaecke, F., Fagel, N., \& Claeys, P. (2011). Lead isotopic analysis for the identification of Late Bronze Age pottery from Hala Sultan Tekke (Cyprus). Archaeometry, 53, 37-57.

Szökefalvi-Nagy, Z., Demeter, I., Kocsonya, A., \& Kovács, I. (2004). Non-destructive XRF analysis of paintings. Nuclear Instruments and Methods in Physics Research Section B: Beam Interactions with Materials and Atoms, 226, 53-59.

Tripathi, J.K., \& Rajamani, V. (2007). Geochemistry and origin of ferruginous nodules in weathered granodioritic gneisses, Mysore Plateau, southern India. Geochimica et Cosmochimica Acta, 71, 1674-1688.

Varga, K., Hunyadi, I., Hakl, J., Uzonyi, I., \& Bacsû, J. (1995). Gross alpha radioactivity and chemical trace element content of thermal waters measured by SSNTD and XRF methods. Radiation Measurements $25,577-580$.

West, M., Ellis, A.T., Potts, P.J., Streli, C., Vanhoof, C., Wegrzynek, D., \& Wobrauschek, P. (2010). Atomic spectrometry update-X-ray fluorescence spectrometry. Journal of Analytical Atomic Spectrometry, $25,1503-1545$.

Zambello, F.R., \& Enzweiler, J. (2002). Multi-element analysis of soil and sediments by wavelength-dispersive X-ray fluorescence spectrometry. Journal of Soils and Sediments, 2, 29-36. 